\title{
Functional Binders based on Polymeric lonic Liquids for Sodium Oxygen Batteries using lonic Liquid electrolytes
}

The An $\mathrm{Ha}^{\mathrm{a}}$, Han $\mathrm{Li}^{\mathrm{b}}$, Xiaoen Wang ${ }^{\mathrm{b}}$, Luke A. O’Dell b, Maria Forsyth ${ }^{\mathrm{a}}$, Cristina PozoGonzalo ${ }^{a^{*}}$, Patrick C. Howlett $\mathrm{a}^{*}$

${ }^{a} A R C$ Centre of Excellence for Electromaterials Science, Institute for Frontier Materials, Deakin University, Burwood, Victoria, Australia, 3125.

${ }^{\mathrm{b}}$ Institute for Frontier Materials, Deakin University, Geelong, Victoria, Australia, 3200.

*Corresponding author: Prof. Patrick Howlett and Dr. Cristina Pozo-Gonzalo

Email: Patrick.howlett@deakin.edu.au; cpg@deakin.edu.au 

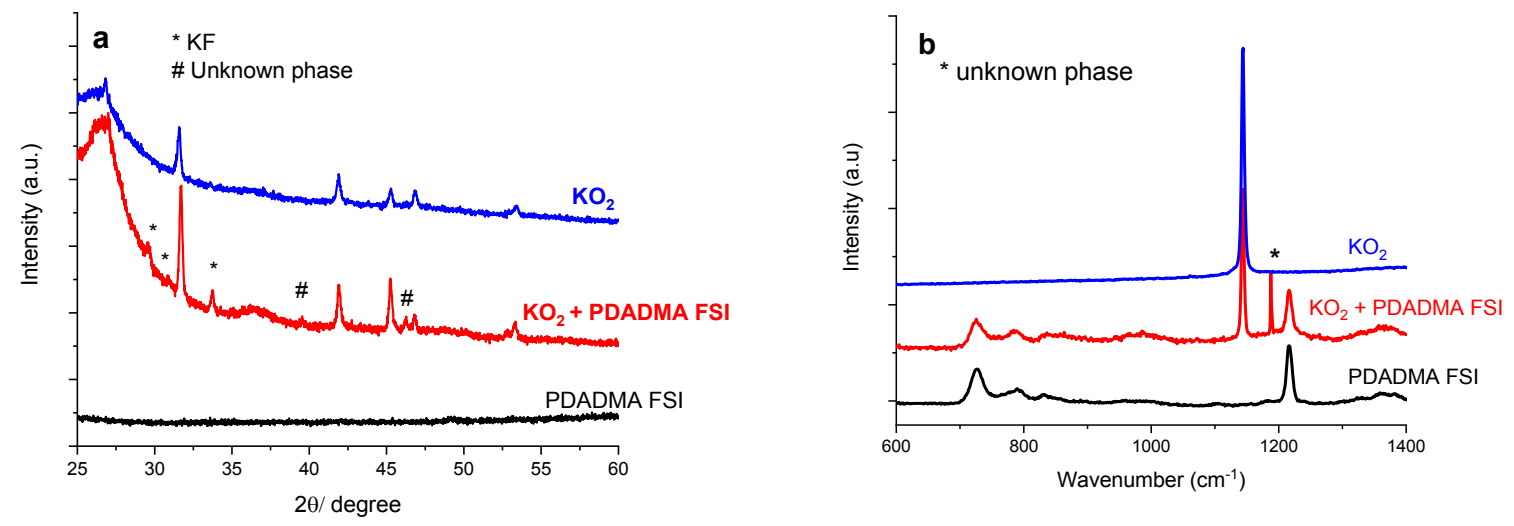

c

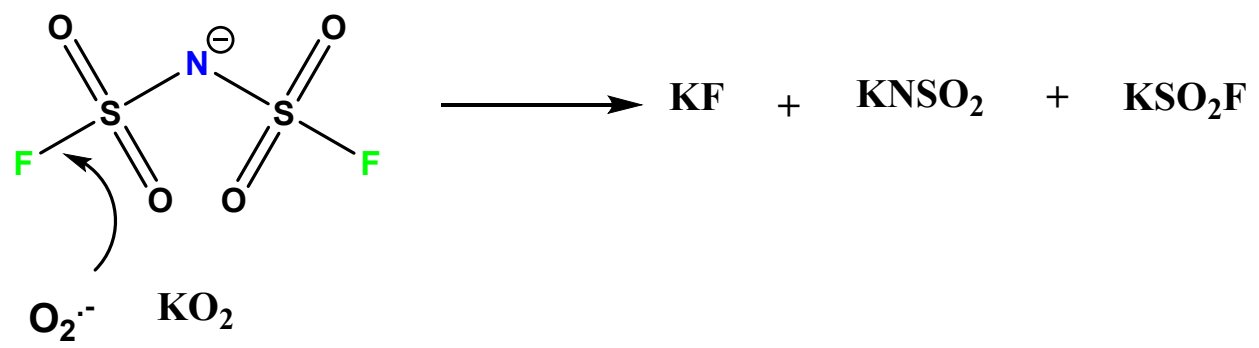

Figure S 1. a -XRD pattern ; b- Raman spectrum showing comparison of PDADMA FSI, condensed the solution of exposed $\mathrm{KO}_{2}$ in PDADMA FSI in $\mathrm{ACN}, \mathrm{KO}_{2}$; c- Proposed mechanism decomposition of $\mathrm{FSI}$ anion in the presence of $\mathrm{KO}_{2}$. 

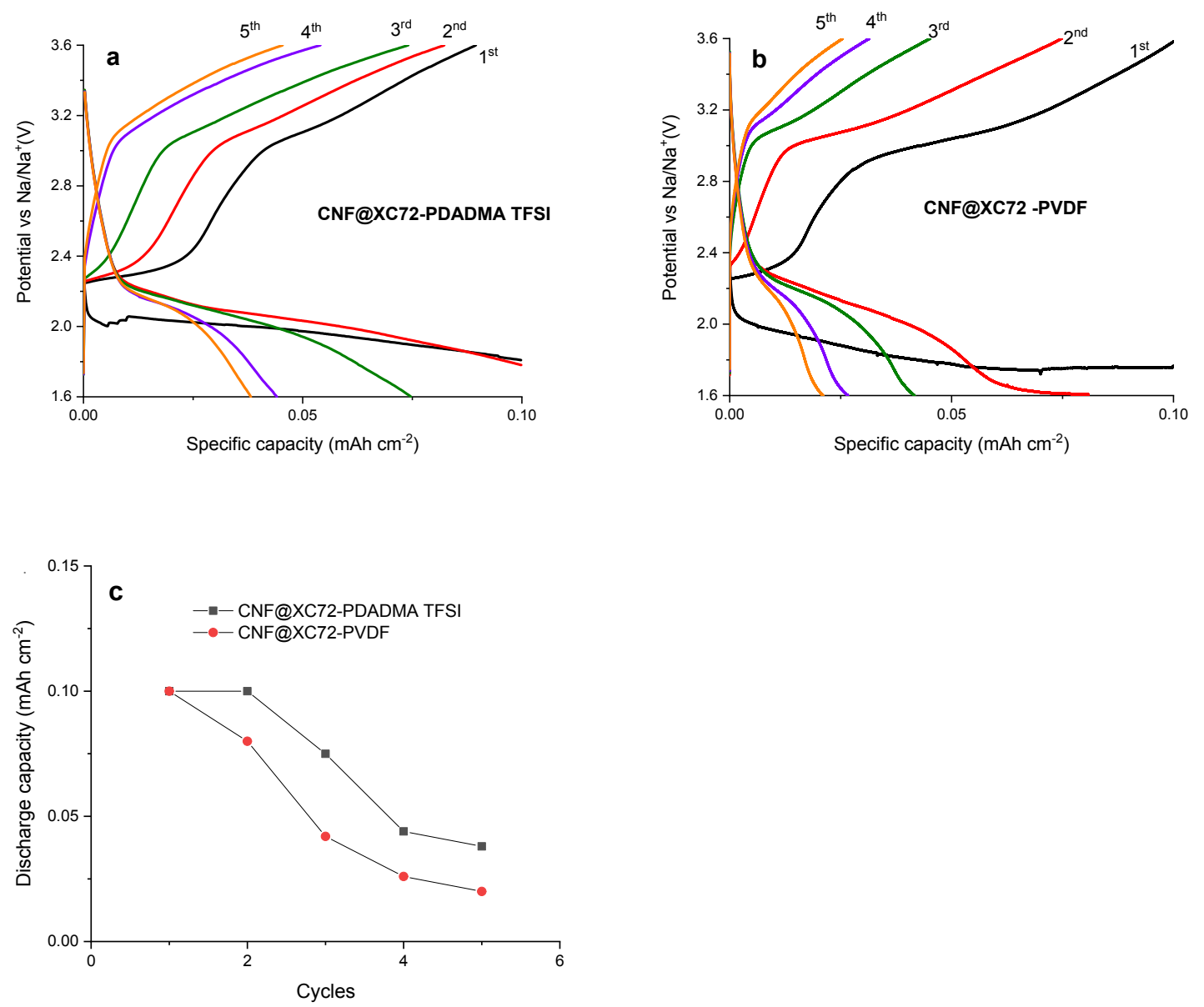

Figure $\mathrm{S}$ 2. Cycling stability of the $\mathrm{Na}-\mathrm{O}_{2}$ cells using the two different air cathodes a) CNF@XC72-PDADMA TFSI; b) CNF@XC72-PVDF; c) comparison of cycling performance of the CNF@XC72-PDADMA TFSI and CNF@XC72-PVDF . Applied current density: $0.1 \mathrm{~mA} \mathrm{~cm}{ }^{-2}$, limited capacity: $0.1 \mathrm{mAh} \mathrm{cm}^{-2}$, cut-off potential $1.6 \mathrm{~V}-3.6 \mathrm{~V}$, working temperature: $60{ }^{\circ} \mathrm{C}$. Electrolyte: 16.6 mol\% NaTFSI in [ $\left.\mathrm{C}_{4} \mathrm{mpyr}\right][\mathrm{TFSI}$. 


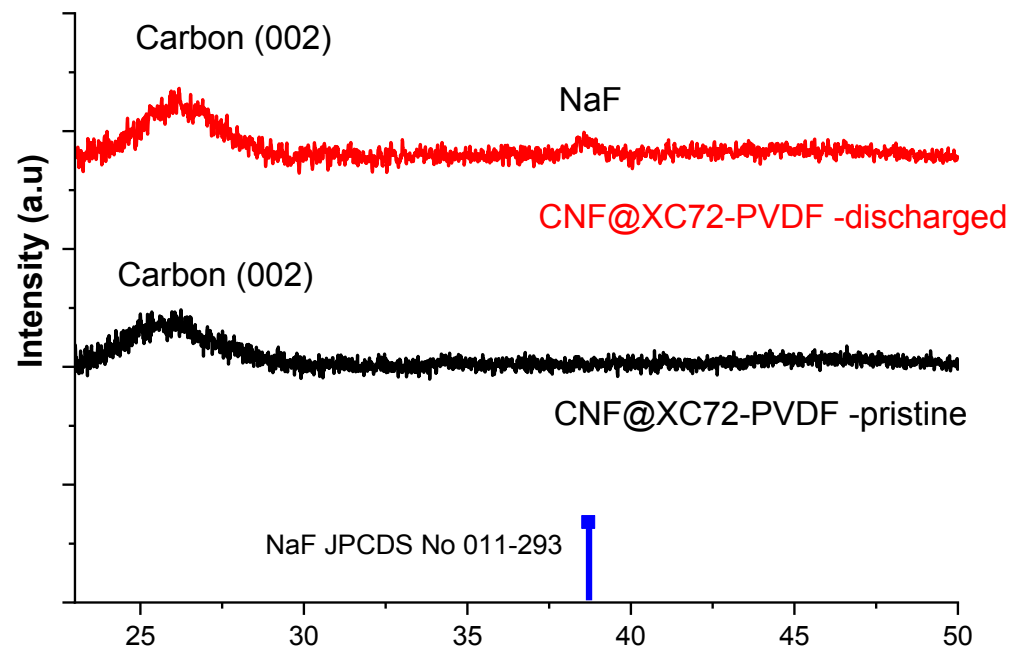

$2 \theta /$ degree

Figure S 3. XRD pattern of the air cathode CNF@XC72-PVDF after discharge at a constant applied current density of $0.1 \mathrm{~mA} \mathrm{~cm}{ }^{-2}$, cut-off potential between $1.6 \mathrm{vs} \mathrm{Na} / \mathrm{Na}^{+}$, working temperature $60^{\circ} \mathrm{C}$. 


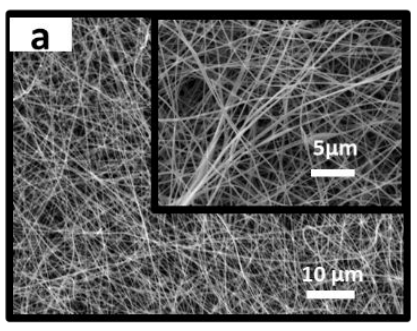

CNF

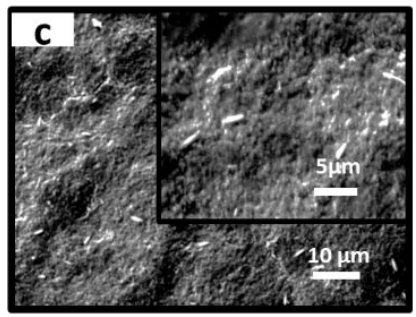

CNF@XC72-DADMATFSI

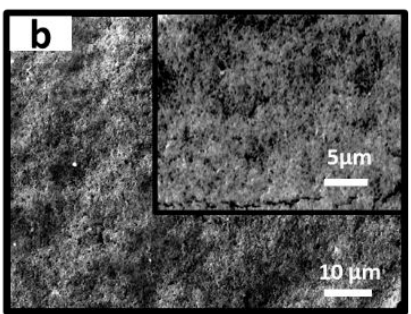

CNF@XC72-PVDF

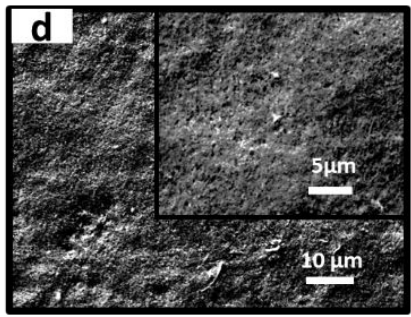

CNF@XC72-PTFE

Figure S 4. SEM micrograph of a- bare CNF electrode, b- XC72 coating CNF based PVDF binder: CNF@XC72-PVDF, c- XC72 coating CNF based PDADMA TFSI binder CNF@XC72-PDADMA TFSI and d- XC72 coating CNF based PTFE binder CNF@XC72-PTFE. 


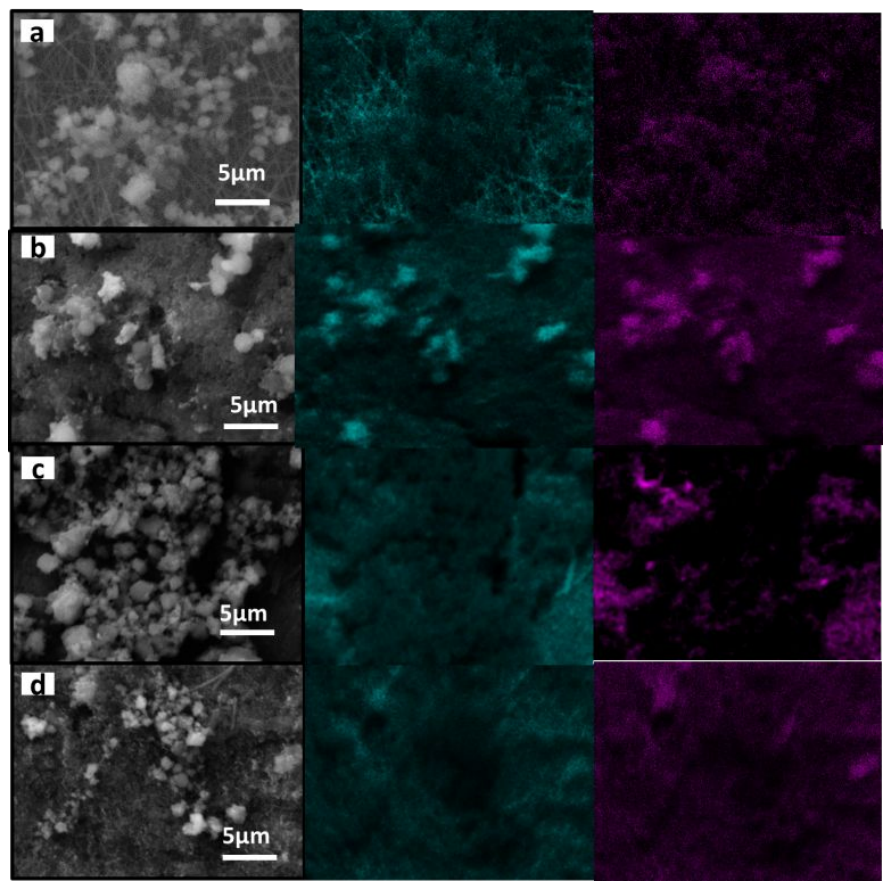

Figure S 5. EDS mapping of the discharge products showing both the morphology and density of the products on the cathodes (left) as well as the presence and distribution of carbon (middle) and fluorine (right) for a-CNF; b-CNF@XC72-PVDF, c- CNF@XC72-PDADMA TFSI and d-CNF@XC72-PTFE. Applied current density $0.1 \mathrm{~mA} \mathrm{~cm}^{-2}$, limited capacity $0.3 \mathrm{mAh} \mathrm{cm} \mathrm{cm}^{-2}$, cut off potential $1.6 \mathrm{~V}$, operation: $60^{\circ} \mathrm{C}$. 

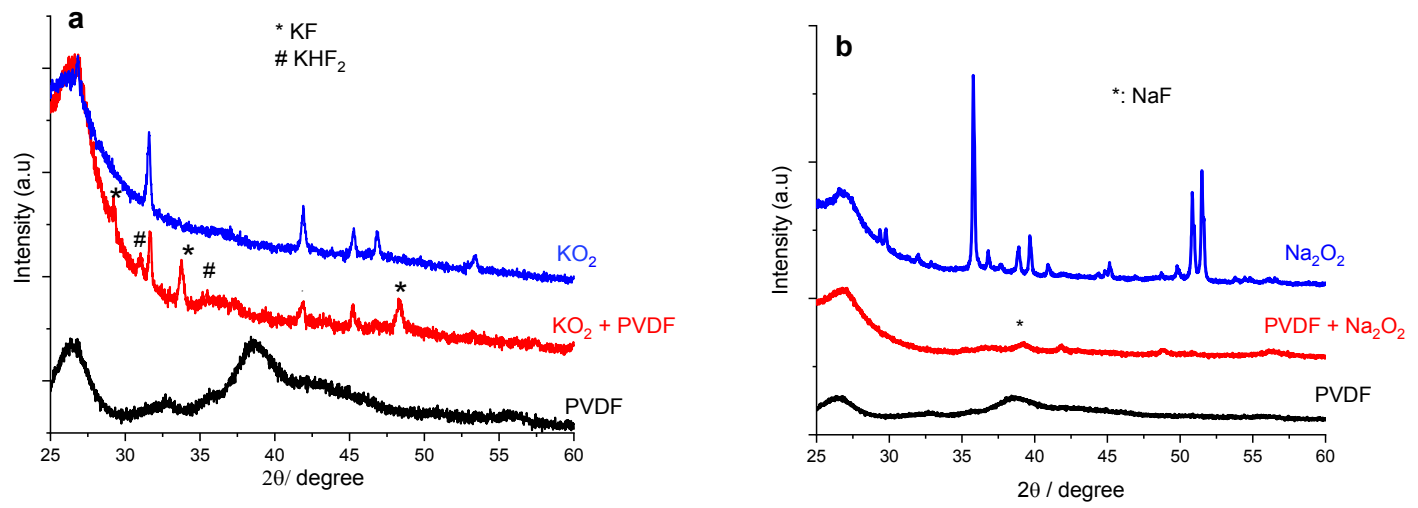

Figure S 6. XRD pattern of showing comparison of a- PVDF condensed solution exposed of $\mathrm{KO}_{2}$ +PVDF in NMP and $\mathrm{KO}_{2} ; \mathrm{b}-\mathrm{PVDF}$, condensed the solution exposed of $\mathrm{Na}_{2} \mathrm{O}_{2}+$ PVDF in NMP and $\mathrm{Na}_{2} \mathrm{O}_{2}$. 

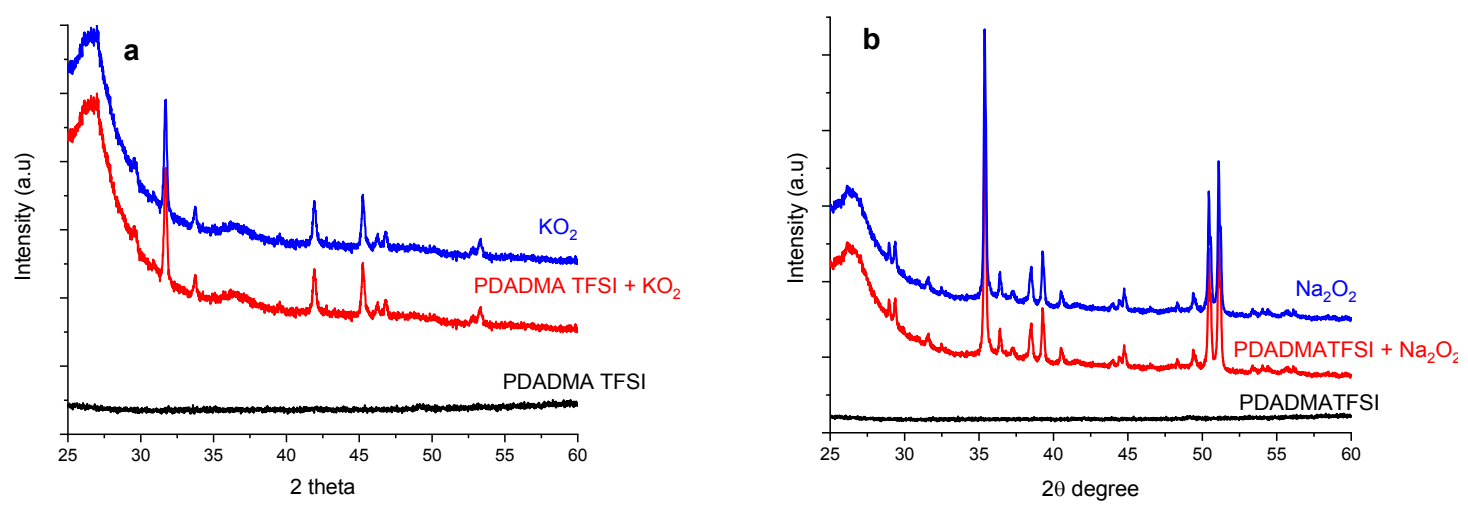

Figure S 7. XRD pattern of showing comparison of a- PDADMA TFSI, condensed solution exposed of $\mathrm{KO}_{2}+$ PDADMA TFSI in ACN and $\mathrm{KO}_{2} ; \mathrm{b}$ - PDADMA TFSI, condensed solution exposed of $\mathrm{Na}_{2} \mathrm{O}_{2}+$ PDADMA TFSI in ACN and $\mathrm{Na}_{2} \mathrm{O}_{2}$ 

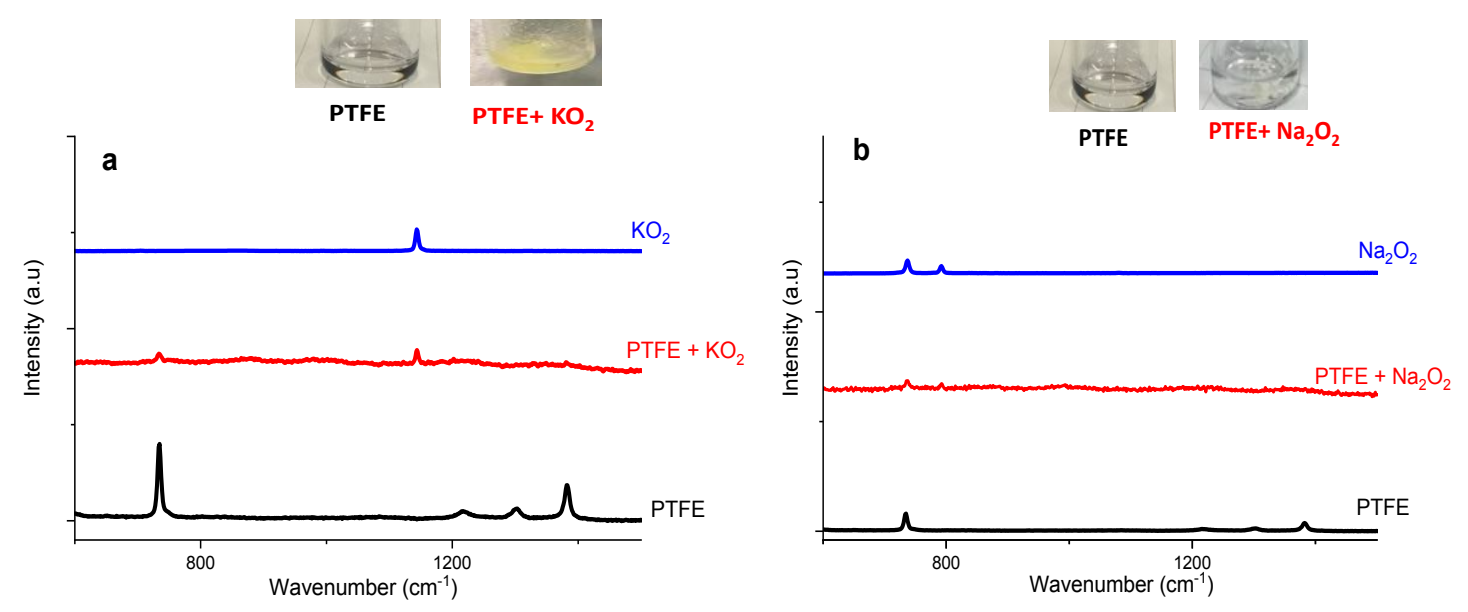

Figure S 8. Raman spectrum showing comparison of a- PTFE, condensed the solution exposed of $\mathrm{KO}_{2}+$ PTFE in ACN and $\mathrm{KO}_{2} ;$ b- PTFE, condensed the solution exposed of $\mathrm{Na}_{2} \mathrm{O}_{2}+$ PTFE in ACN and $\mathrm{Na}_{2} \mathrm{O}_{2}$. 

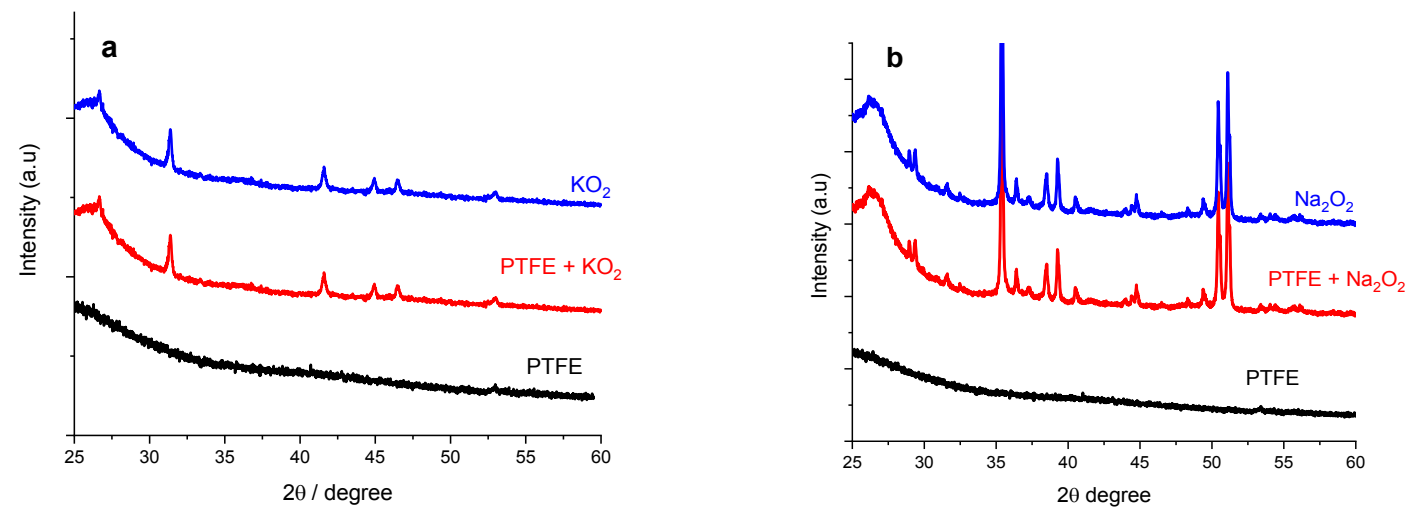

Figure S 9. XRD pattern showing comparison of a- PTFE, condensed the solution exposed of $\mathrm{KO}_{2}+$ PTFE in $\mathrm{ACN}$ and $\mathrm{KO}_{2} ; \mathrm{b}$ - PTFE, condensed the solution exposed of $\mathrm{Na}_{2} \mathrm{O}_{2}+$ PTFE in ACN and $\mathrm{Na}_{2} \mathrm{O}_{2}$. 